\title{
Design-Build Project Approach in a First Year Engineering Design Course
}

\author{
George Platanitis and Remon Pop-Iliev \\ University of Ontario Institute of Technology \\ george.platanitis@uoit.ca \\ remon.pop-iliev@uoit.ca
}

\begin{abstract}
We found that first-year engineering students often have difficulties to visualize and manipulate threedimensional objects mentally, especially if the assembly involves multiple parts that need to work together in sequence to produce a required function. Ultimately, this lack of ability leads to poor representation of intended students' design concepts in paper sketches, as well as poor or unacceptable detailed designs in CAD. Therefore, it is imperative that students develop their ability to manipulate complex objects in space very early in their academic careers. In this context, this paper focuses on the introduction and implementation of a challenging design-build project in the first-year engineering design course at UOIT intended to provide students with early opportunities to physically realize the spatial relationships and the three dimensional causality of the interaction of moving parts in an assembly.
\end{abstract}

\section{Introduction}

The ability of engineers to mentally visualize a complex system of moving parts is paramount if they are to properly translate the concept from that mental image to a physical artifact that produces the intended function. The process begins with a freehand sketch of the idea, a detailed design using CAD to produce a virtual concept, and finally building the working prototype that represents the original product idea. Therefore, there exists a need to for students to develop visualization skills early in their academic careers, such that they can turn and manipulate the product, open it up to see the internal components, and mentally "see" the different parts of the assembled product move in the appropriate sequence required to produce the intended function, that is, visualize the relationship between the moving parts. Development of this skill ultimately leads to more efficient iteration of the design.

Students enrolled in the undergraduate engineering program at the University of Ontario Institute of Technology take three core design courses, one in each of their first three years, and a final year capstone course. As they progress through these courses, the term design projects increase in complexity, with the final products containing an increased number of moving components and functions each year [1],[2],[3],[4]; thus, visualization and spatial thinking skills become ever more crucial so that students can conceive feasible designs and functioning products.

Traditionally, students enrolled in the first-year core course (where they learn fundamental concepts in engineering graphics, 3D modelling and visualization, freehand sketching, CAD functions, and product design and development concepts) were assigned to redesign and reverse-engineer an existing artifact, requiring only a virtual prototype in CAD to demonstrate feasibility of their design [1]. However, beginning with the Fall 2009 offering of the course, students were charged with a unique opportunity to design automata devices that would be manually powered to animate several characters in a logical sequence and realize their designs physically by building a functioning prototype of their automata devices. This paper will describe this design-build implementation. By introducing a design-build project in the first-year core course, students would need to work spatially between freehand sketching, detailed design in $\mathrm{CAD}$, and prototyping if they are to ensure the feasibility and proper functionality of their artifact.

\section{Spatial Thinking}

The ability to think with images is often lacking in classroom instruction of science and engineering, and students historically have failed to demonstrate fundamental understanding required to advance to new 
topics where visual-spatial thinking is needed. Examples include the nature of shadows and reflections, relative motion and frame-of-reference orientation [5]. Thinking skills, including imagery, must be addressed as part of curriculum reform.

One of the few courses that exist in academia that provides opportunity for students to develop and use spatial thinking and visualization skills is offered at Simon Fraser University, British Columbia. The course was established to allow students of diverse backgrounds the opportunity to establish a foundation of skills for spatial thinking and communication. Students completing this course would be able to [6]:

- Use graphical representation and communication,

- Visualize, examine and interpret 3D representations,

- Create and manipulate 2D and 3D representations,

- Build digital and physical models, and

- Communicate spatial thinking in different design contexts.

Based on this approach, first-year students at UOIT enrolled in the Engineering Graphics and Design course were introduced to a group term project in which they were required to design and build a manually-powered automata device. In contrast to previous offerings of the course that only focused on the conceptual development and on demonstrating the feasibility of students' designs via virtual prototyping i.e., through simulations based on manipulating the CAD model utilizing the motion capabilities of the software, the new format focuses on the designing and prototype building of automata devices which require a manual-powered input to move/animate several characters in a meaningful sequence of events as per students' free choice. Students have found the experience beneficial, having been afforded the opportunity to convert their virtual models into fully functioning physical artifacts.

\section{Automata Design Project}

Automata have existed for many years, and historic findings of automata designs of which have provided useful functions [7] have been documented. Another notable automaton with historical significance is the mechanical monk [8], driven by a key-wound spring. Automata design has also become a tool for developing children's interest in engineering, as presented in [9]. Here, the authors introduce elementary and middle school children to automata design, providing them with computational design tools (MachineShop) combined with novel fabrication devices (laser cutter) for the students to realize their automata designs. Introducing an automata designbuild project to first-year engineering students is expected to not only improve their spatial visualization skills and enhance creativity, but to also provide them an opportunity to physically realize their designs.

The group term design project assigned to firstyear students required them to design and build a moderately complex system, more specifically an automata device, with multiple moving parts, where some part motions are dependent on others. As a consequence, for the system to function properly, students needed to consider many factors, including the shape of the parts, part-whole relationships, topological structures, and spatial interactions of the parts.

The automata device was required to perform a unique, meaningful task/theme (i.e., tell a story), limited only by the creativity and imagination of the students. The motions of the various components must produce moderately complex activities that move a series of figures or characters. Students proposed their own original creation for their respective automata devices that would animate a theme of their choice. Similar to previous first-year design projects, students were not required to perform any material and stress analysis (that is, material would be assumed infinitely strong).

\subsection{Project Requirements}

The requirements of the automata design-build project can be summarized as follows:

- $\quad$ Requirement 1: The Automata device must have at least five figures/characters that will move in a particular manner to produce an animation, with at least three figure motions being dependent on each other.

- Requirement 2: Develop at least five alternative concept maps [10] to show the relationships between each of the moving figures, as well as the parts-to-whole relationship. From these maps, decide which would be the best (optimal) to use to guide the design.

- Requirement 3: Design gears, cams, shafts, and any other components necessary to produce the animation for all the figures. These components will move by way of a crank wheel that can be rotated manually.

- $\quad$ Requirement 4: Build a working prototype of the Automata device, that you will be required to demonstrate during your oral presentation. 
Deliverables for this project included various forms of documentation of the design, which included a complete set of engineering drawings that completely describe the automata mechanism, while obeying ANSI standards for Engineering Graphics. In this respect, students were to provide at least: a 3D assembly with motion functionality, 3D and respective 2D multiview drawings of all its subassemblies, components, and parts (including dimensions, tolerances, and tentative bills of materials) using Unigraphics NX5. Drawings must be in sufficient detail so that a remotely located manufacturer would be able to produce it without further intervention. Finally, students were to provide a single-page marketing brochure to describe the basic automata assembly, function and general maintenance including, for example, rendered NX5 3D drawings. Finally, students were required to produce a formal engineering report discussing their design and how it satisfies the requirements and to prepare and give an in-class oral presentation, which also included a demonstration of the automata prototype.

The design projects were then graded based on a rubric specifically designed for first-year project evaluation [11].

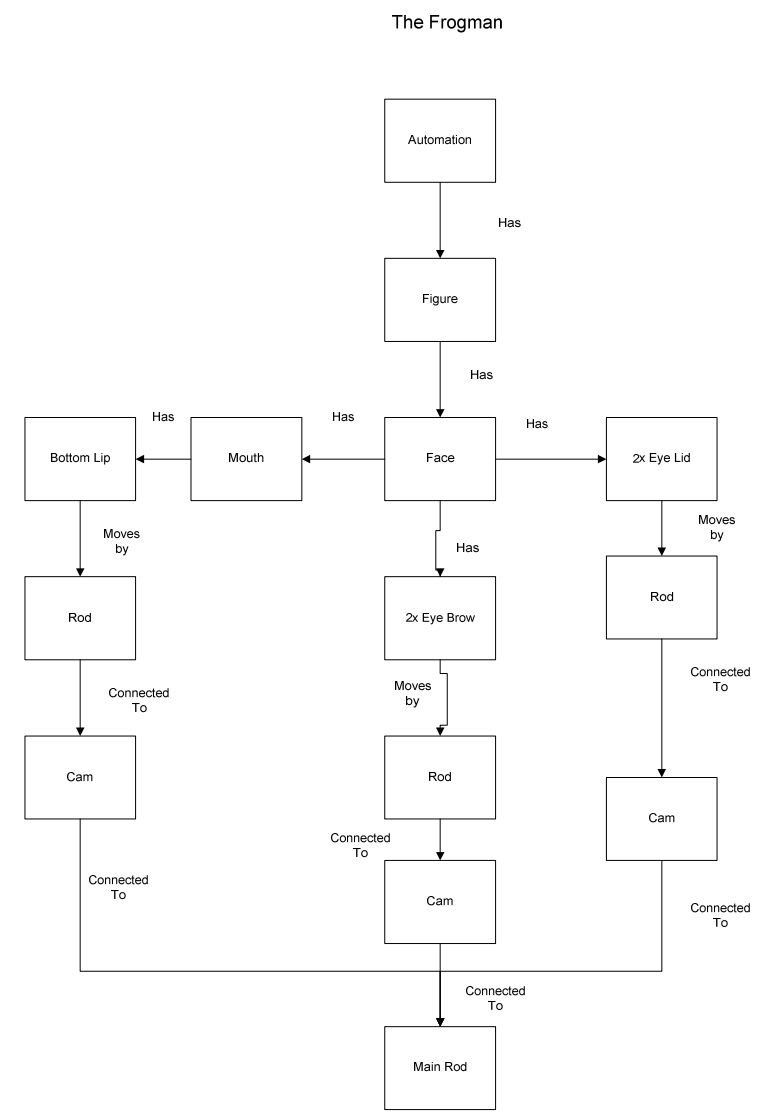

Figure 1. Example of a concept map outlining organization of figures and their dependencies.

\subsection{Example Results}

An example of the automata project designs submitted by the students is presented in this section. The design entails the organization of figures such that, when the crank is turned, they show the animation of a frog face, with eyes blinking independently, a mouth opening and closing, and the movement of eyebrows synchronized to the blinking eyes. Figure 1 shows an example of one of the requirements, which is a concept map outlining the intended process of the animation, which figures depend on one and other and in what sequence, and which figures move independently.

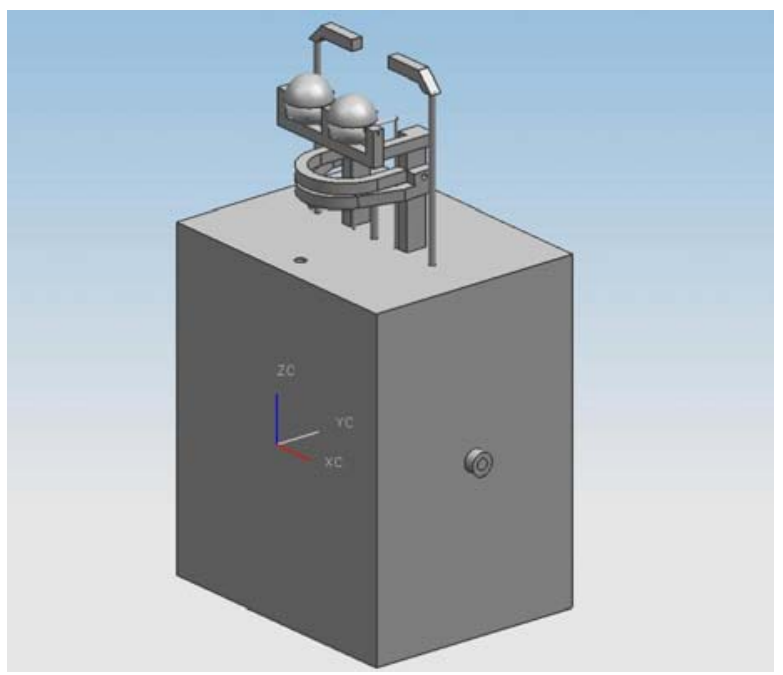

Figure 2. CAD rendering in NX5 of automata depicting relationship between figures animating frog face.

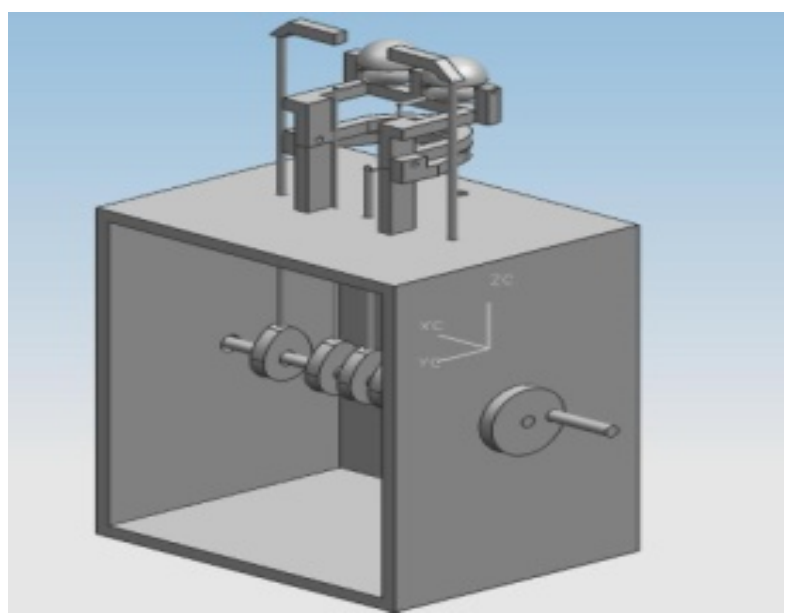

Figure 3. Alternate view of CAD rendering of automata showing internal components connected to animated figures. 
Figure 2 is a detailed CAD rendering in NX5 of the design showing the orientation of each figure to be animated. Figure 3 is also provided to show a different view of the automata design, such that the internal mechanisms (cams, shafts, etc.) are also visible. Figures 4 and 5 show two views of the final construction of the automata, a front view and a rear view revealing the arrangement of gears, cams, shafts, etc. responsible for the animation.

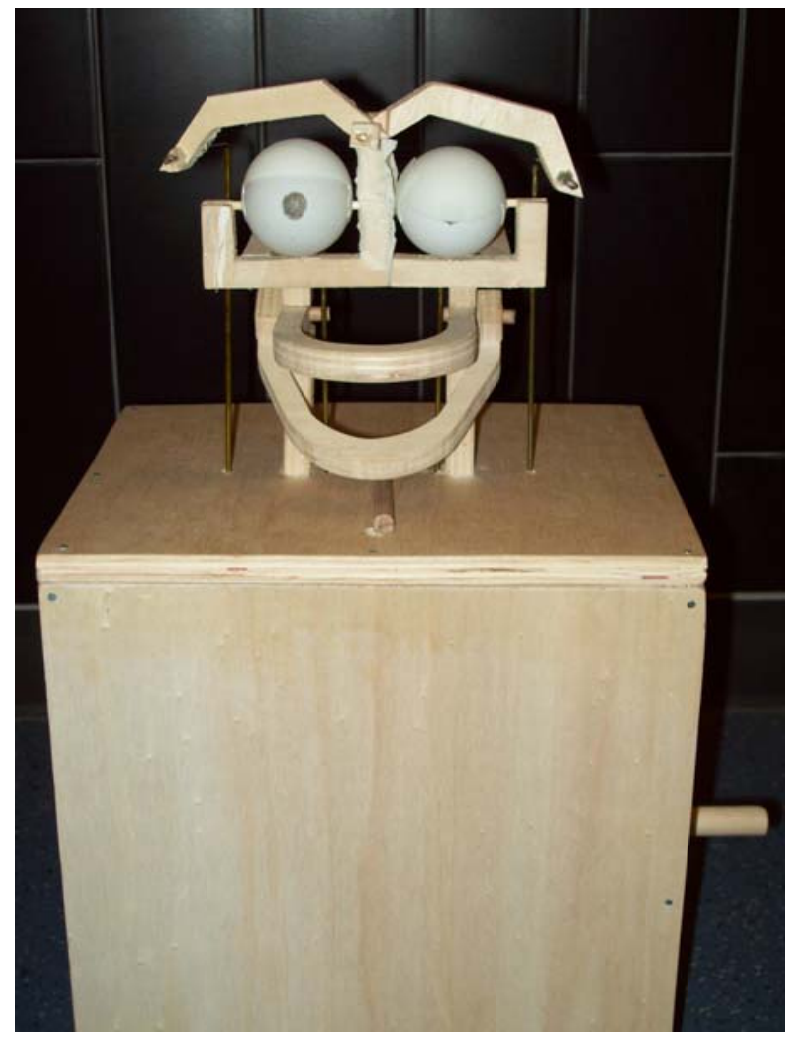

Figure 4. Front view of prototype model of automata device.

\section{Conclusions}

The introduction of the design-build automata device term project into the first-year engineering core design course has proven beneficial. Unlike in previous offerings of the course, where students were only required to produce a virtual design in CAD to prove concept design feasibility, students were able to take advantage of the opportunity to physically realize their designs. The design project required students to think spatially as they visualized the various components constituting their automata, their orientation in space, their relationship to each other, and their relative motion to each other to produce the required animation. As such, students worked spatially between freehand sketches, detailed CAD design, and prototyping to produce a working automata device.

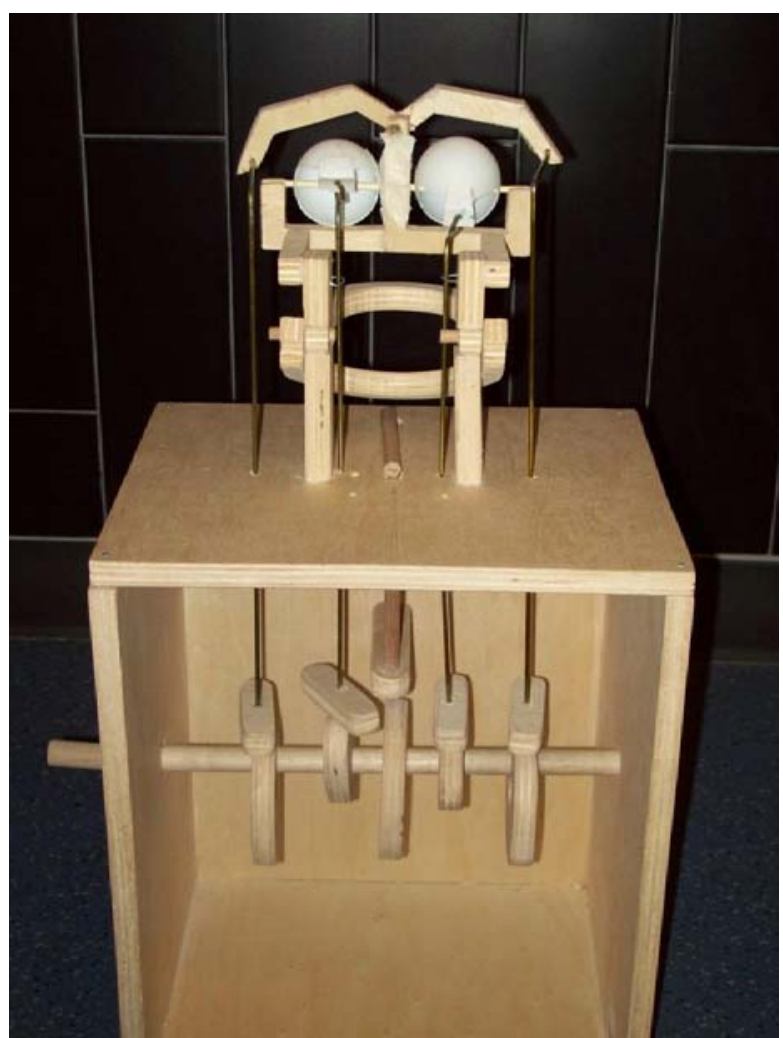

Figure 5. Rear view of prototype model of automata device showing arrangement of shafts, cams, etc. responsible for animation of figures.

\section{Acknowledgements}

The authors would like to thank the Natural Sciences and Engineering Research Council (NSERC) of Canada, General Motors Canada Limited (GMCL), and UOIT for financially supporting UOIT's Design Chair budget, part of which supported this research work. The authors are also grateful for the hardware and software provided by PACE (Partners for the Advancement of Collaborative Engineering Education).

\section{References}

[1] S.B. Nokleby and R. Pop-Iliev, "A Design Challenge-Incorporating Design into the First Year Engineering Curriculum," The $2^{\text {nd }} C D E N / R C C I$ International Conference on Design Education, Innovation, and Practice, Kananaskis, Alberta, Canada, July 18-20, 2005. 6 pages. 
[2] R. Pop-Iliev and S.B. Nokleby, "Concurrent Approach to Teaching Concurrent Design Engineering," The $2^{\text {nd }}$ CDEN/RCCI International Conference on Design Education, Innovation, and Practice, Kananaskis, Alberta, Canada, July 18-20, 2005. 10 pages.

[3] R. Pop-Iliev and S.B. Nokleby, "Cross-Course Integrated Group Design Projects: $1+1=11$," The $3^{\text {rd }}$ CDEN/RCCI International Design Conference, University of Toronto, Ontario, Canada, July 2426, 2006. pp. 303-308.

[4] R. Pop-Iliev. and G. Platanitis, "Training WellEquipped Design-Ready Engineering Professionals," The $9^{\text {th }}$ International Conference on Engineering and Product Design Education (EDPE07), Newcastle upon Tyne, United Kingdom, September 13-14, 2007. pp. 129-134.

[5] J.H Mathewson, "Visual-Spatial Thinking: An Aspect of Science Overlooked by Educators," Science Education, Vol. 83, No. 1, 1999. pp. 3354.

[6] H. Erhan, B.B. Youssef, M. Sjoerdsma, J. Dill, B. Berry, J. McCracken, "Spatial Thinking and Communicating: A Course for First-Year University Students," The $5^{\text {th }}$ Canadian Design Engineering Network Conference, Halifax, Ontario, Canada, July 27-29, 2008. 8 pages.

[7] G. Nadarajan, "Islamic Automation: A Reading of Al-Jazari's The Book of Knowledge of Ingenious Mechanical Devices (1206)", Foundation for Science, Technology, and Civilisation, August 2007. 16 pages.

[8] E. King, "Clockwork Prayer: A Sixteenth-Century Mechanical Monk,” Blackbird, an Online journal of Literature and the Arts, Vol. 1, No. 1, Spring 2002. 27 pages. Online version: http://www.blackbird.vcu.edu/v1n1/nonfiction/kin g_e/prayer_introduction-still.htm.

[9] G. Blauvelt and M. Eisenberg, “Computer-Aided Design of Mechanical Automata: Engineering Education for Children,” International Conference on Education Technology (ICET), Calgary, Alberta, Canada, July 17-19, 2006. 6 pages.

[10] J.D. Novak, “Concept Maps and Vee Diagrams: Two Metacognitive Tools to Facilitate Meaningful
Learning," Instructional Science, Vol. 19, No. 1, January 1990. pp. 29-52.

[11] G. Platanitis and R. Pop-Iliev, “Assessment and Evaluations of Undergraduate Design Engineering Projects," Proceedings of the ASME 2007 International Design Engineering Technical Conferences \& Computers and Information in Engineering Conference (IDETC/CIE 2007), Las Vegas, Nevada, September 4-7, 2007. 10 pages. 